\title{
DISPOSITIVOS DIDÁTICOS PARA 0 ENSINO/APRENDIZAGEM DE LÍNGUA PORTUGUESA
}

\author{
DIDACTIC DEVICES FOR PORTUGUESE LANGUAGE TEACHING AND LEARNING
}
DISPOSITIVOS DIDÁCTICOS PARA LA ENSEÑANZA-APRENDIZAJE DE LENGUA PORTUGUESA

Thassiana Reis Félix*

Maria Ilza Zirondi*

\begin{abstract}
Resumo: Este artigo tem como objetivo discutir como dispositivos didáticos podem auxiliar o professor a organizar seu trabalho de ensino da Língua Portuguesa. Para isso, analisaremos um Projeto de Letramento ( $\mathrm{PL}^{1}$ ), uma Sequência Didática (SD) e uma Prática de Letramento ( $\mathrm{PL}^{2}$ ). Como embasamento teórico-metodológico nos pautaremos na teoria sociointeracionista de Vigotski,, em autores como Dolz; Noverraz e Schneuwly (2013), Kleiman (2007) e outros. Esperamos, desta forma, buscar reflexões a respeito de como um $\mathrm{PL}^{1}$, uma $\mathrm{SD}$ e uma $\mathrm{PL}^{2}$ se organizam e se constituem como instrumentos do trabalho pedagógico, das atividades didáticas, dos conteúdos escolares para, consequentemente, desenvolver nos alunos capacidades em relação à leitura, à escrita e à oralidade.
\end{abstract}

Palavras-chave: Dispositivos didáticos. Trabalho docente. Língua Portuguesa.

Abstract: This article aims to discuss how didactic devices can help teachers to organize their work in Portuguese teaching. Thereunto, we are going to analyze a Literacy Project (LP $\left.{ }^{1}\right)$, a Didactic Sequence (DS) and a Literacy Practice ( $\mathrm{LP}^{2}$ ). As theoretical and methodological basis, we are going to follow the social interactionist theory (Vygotsky) found on authors such as Dolz; Noverraz and Schneuwly (2013), Kleiman (2007) and others. We intend, this way, seek reflections on how a LP ${ }^{1}$, a DS and a $\mathrm{LP}^{2}$ can be organized and constituted as pedagogical work instruments of didactic activities and school contents to, consequently, developing in the students skills related to reading, writing and speaking.

Keywords: Didactic devices. Teaching work. Portuguese language.

Resumen: Este artículo tiene como objetivo discutir cómo dispositivos didácticos pueden auxiliar el profesor a organizar su trabajo de enseñanza de la Lengua Portuguesa. Para eso, analizaremos un Proyecto de Letramento ( $\left.\mathrm{PL}^{1}\right)$, una Secuencia Didáctica (SD) y una Práctica de Letramento ( $\left.\mathrm{PL}^{2}\right)$. Como embasamiento teórico-metodológico nos pautaremos en la teoría socio-interaccionista de Vigotski, como Dolz; Noverraz e Schneuwly (2013), Kleiman (2007) y otros. Esperamos, así, buscar reflexiones a respeto de cómo un $\mathrm{PL}^{1}$, una $\mathrm{SD}$ y una $\mathrm{PL}^{2}$ se organizan y se constituyen como instrumentos del trabajo pedagógico, de las actividades didácticas, de los contenidos escolares para, consecuentemente, desarrollar en los alumnos capacidades en relación a la lectura, a la escrita y a la oralidad.

Palabras-clave: Dispositivos didácticos. Trabajo docente. Lengua Portuguesa.

"Universidade Estadual de Londrina - UEL. Email: thassi_05_1988@hotmail.com

**Universidade Estadual de Londrina - UEL. Email: ilzamaria2000@yahoo.com.br 


\section{Introdução}

Diante das diferentes práticas/estratégias presentes no ensino com a finalidade de organizar o trabalho do professor, este trabalho tem como objetivo discutir três dispositivos didáticos considerados tanto como mediadores quanto norteadores do ensino-aprendizagem: os Projetos de Letramento, as Sequências Didáticas e as Práticas de Letramento (doravante $\mathrm{PL}^{1}, \mathrm{SD}$ e $\mathrm{PL}^{2}$, respectivamente).

A escolha para esse estudo se justifica por serem esses dispositivos os mais citados em documentos oficiais e prescritivos, a exemplo dos Parâmetros Curriculares Nacionais (PCN) (BRASIL, 1998), e por gerarem dúvidas na/para organização do trabalho do professor e, consequentemente, para o ensino de Língua Portuguesa.

Nas últimas décadas, vários impactos ocorreram em relação à reflexão sobre o ensino de língua materna. Um deles foi a implementação de modelos didáticos em contraposição com o "modelo de ensino" anterior, visto como conteudístico e desvinculado do mundo social. A partir disso, houve uma contribuição para que os professores começassem a desejar mudar sua prática em sala de aula, abandonando a ideia de que era conhecedor da língua aquele que era capaz de classificar palavras e orações e, deste modo, privilegiar o ensino através do uso de textos e, posteriormente, a grande questão foi trabalhar textos em uma perspectiva de gêneros. (TINOCO, 2008).

Diante desse quadro, diferentes abordagens e perspectivas de desenvolvimento das práticas pedagógicas passaram a ser discutidas no sentido de contribuir para o trabalho com o gênero textual e com a linguagem. Devido a essa diversidade e com o surgimento de novos termos, houve certa confusão em relação às diferentes propostas teóricas e metodológicas relativas ao assunto. Portanto, este trabalho se justifica por ter o objetivo de buscar reflexões sobre como esses dispositivos didáticos citados anteriormente podem contribuir para a elaboração e a organização do trabalho do professor.

Os questionamentos que norteiam nosso trabalho são: I) O que seria e como são organizados os $\mathrm{PL}^{1}$, as $\mathrm{SD}$ e as $\mathrm{PL}^{2}$ ?; II) Quais os objetivos educacionais dos dispositivos didáticos?; III) Como o trabalho do professor pode ser organizado a partir desses diferentes dispositivos?

Para buscarmos essas respostas, este artigo será organizado da seguinte forma: primeiramente, abordando a concepção de linguagem sociointeracionista de Vigotsky e a relação com/apresentação(d)os dispositivos didáticos abordados neste trabalho; em segundo, compreendendo toda metodologia: tipo de pesquisa, corpus e categorias utilizadas para as análises; depois, a análise dos dados, com os aspectos observáveis concernentes aos PL ${ }^{1}$, as SD e as $\mathrm{PL}^{2}$; por fim, as considerações finais, momento em que faremos uma reflexão sobre o que foi apresentado neste artigo.

\section{Concepção sociointeracionista da linguagem}

Este trabalho se insere em uma abordagem sociointeracionista da linguagem. Portanto, partiremos das concepções de Lev Vigotsky (1987), cuja maior preocupação relacionava-se ao desenvolvimento do pensamento e da consciência do indivíduo que, segundo ele, só se tornaria possível através da interação social ocorrida por meio da linguagem, considerada a ferramenta básica para a construção de conhecimentos.

Para Vigotsky, o indivíduo não é como um receptáculo vazio, mas um sujeito 
interativo, capaz de constituir conhecimento e se constituir a partir de relações inter e intrapessoais. Devido ao fato de a linguagem, principal mediadora entre o sujeito e o objeto do conhecimento, estar em constante evolução, uma vez que a cada situação de interação adquire novas conotações e possibilidades de interpretação, o desenvolvimento desses conhecimentos não se estabelece de forma definitiva, mas gradual (VIGOTSKY, 1987), acontecendo, assim, durante toda a vida do indivíduo.

Vigotsky investigou também como ocorre a formulação de conceitos que são adquiridos pelo indivíduo. Com essa investigação, o autor chegou a dois tipos: os conceitos cotidianos e os científicos. O primeiro - conceitos cotidianos - acontece a partir do que a criança é capaz de formular através da utilização da linguagem durante seu processo de desenvolvimento. Um exemplo seria a nomeação de objetos e fatos presentes em sua vida diária. Por outro lado, os conceitos científicos podem ser formulados através de atividades sistematizadas, acontecendo, assim, a partir do momento em que a criança começa a fazer parte do ambiente escolar. Desta forma, de acordo com o autor, farão parte desse tipo de conceito tudo o que deriva de um corpo articulado de conhecimento e que aparece nas propostas curriculares como fundamental na organização dos conteúdos a serem trabalhados pelos alunos (VIGOTSKY, 1987).

Quanto a esses dois conceitos, o autor defendia que apesar da formulação dos conceitos cotidianos - fora do ambiente escolar - serem importantes para o desenvolvimento da criança, a aprendizagem escolar possui um valor significativo, pois é por meio do auxílio, explicação e colaboração dos professores que o aluno chega à definição dos conceitos científicos e, através da realização das atividades escolares, pode apropriar-se deles. No ambiente escolar, essas atividades, muito provavelmente, são propostas através do uso de diversos textos, inseridos em diferentes gêneros. Desta forma, textos ou gêneros de textos tornam-se os responsáveis pela interação formada pela tríade: criança, aprendizagem e o trabalho do professor.

Partindo da ideia de Vigotsky, Schneuwly (2013) aborda o gênero de texto como instrumento entre a mediação entre o aluno, o aprendizado e o professor. Para o autor,

Os instrumentos encontram-se entre o indi-
víduo que age e o objeto sobre o qual ou a
situação na qual ele age: eles determinam
seu comportamento, guiam-no, afinam e
diferenciam sua percepção da situação na
qual ele é levado a agir. A intervenção do
instrumento - objeto socialmente elaborado
- nessa estrutura diferenciada dá à ativida-
de uma certa forma; a transformação do
instrumento transforma evidentemente as
maneiras de nos comportamos numa situ-
ação (SCHNEUWLY, 2013, p.21).

Ao serem considerados dessa forma, os gêneros são vistos como objetos mediadores da comunicação entre os indivíduos; entretanto, só serão úteis dessa maneira a partir do momento em que o sujeito se apropriar deles. Com essa apropriação, esses instrumentos promoveriam o desenvolvimento do indivíduo, pois a cada nova situação de interação, o sujeito precisaria não apenas adotar, mas adaptar o gênero a ser utilizado, de acordo com suas intenções e necessidades. Assim, a apropriação do instrumento pela criança pode ser vista como "um processo de instrumentalização que provoca novos conhecimentos e saberes, que abre novas possibilidades de ações” a cada nova situação de linguagem (SCHNEUWLY, 2013).

Para que esses textos ou gêneros possam ser trabalhados em sala de aula, Nascimento (2011) afirma que é preciso que 
ocorra o processo de transposição didática. Esse processo, de acordo com a autora,

designa o conjunto de procedimentos destinado a transformar um saber socialmente legitimado (um conceito, uma teoria, um procedimento, etc.), originário de qualquer área do conhecimento num objeto de ensino e aprendizagem possível, considerando o projeto didático em jogo e as capacidades do aprendiz. Esse processo envolve a articulação entre o saber de referência, as demandas sociais do ensino-aprendizagem e as possibilidades do aluno. (NASCIMENTO, 2011, p.428-429).

Desta maneira, a transposição didática, considerada como a necessidade de transpor didaticamente um conteúdo científico em conteúdo escolar, depende de uma avaliação do professor sobre o contexto em que estará inserido. A autora divide essa avaliação para a transposição didática em três níveis:

Em um primeiro nível, identifica o processo de seleção de certos aspectos do saber científico como conteúdos passíveis de formar parte do currículo escolar. Um segundo nível constituiria o conjunto de transformações que se operam no saber adaptado como conteúdo a ensinar no contexto escolar, transformando-se em objeto de ensino. E no terceiro nível - o do sistema didático - onde se encontram professor e alunos é que se presentificam os objetos de conhecimento nas diferentes atividades que se desenvolvem (mediadas pelos instrumentos e pelos comandos reguladores do professor). Nesse terceiro nível se encontram os pólos: professor, alunos e objeto de ensino (NASCIMENTO, 2011).

Portanto, para cumprir esses níveis é preciso que o professor organize seu trabalho em sala de aula. Como menciona Nascimento, nesse primeiro nível estariam os conteúdos ensináveis, que, selecionados pelo professor, passariam por um processo de "adequação" para o contexto, cumprindo assim objetivos educacionais. Essa adequação se refere às diferentes formas de organização desses conteúdos e o percurso a ser percorrido para que os alunos alcancem a aprendizagem. Esse seria o segundo nível e é nele que o professor toma determinadas decisões organizando os conteúdos de acordo com propósitos e objetivos de aprendizagem. Diante disso, acreditamos que podem assumir importante papel organizacional, pois é após essa organização que temos o desenvolvimento das atividades mediadas por instrumentos que, para o trabalho do professor, chamaremos de dispositivos didáticos. Desta forma, há uma relação entre esses dispositivos e os conceitos científicos abordados por Vigotsky (1987), pois será através das atividades elaboradas/ apresentadas pelo professor que ocorrerão novos saberes e conhecimentos por parte dos alunos.

A concepção sociointeracionista de Vigotsky (1987) permeia os documentos oficiais de ensino. De acordo com os PCN (BRASIL, 1998), ao considerar a linguagem como atividade discursiva, o texto como objeto de ensino e a noção de gramática como relativa ao conhecimento que o falante tem de sua linguagem, as atividades curriculares em Língua Portuguesa correspondem, principalmente, a atividades discursivas, ou seja, a

uma prática constante de escuta de textos orais e leituras de textos escritos e de produção de textos orais e escritos, que devem permitir, por meio da análise e reflexão sobre os múltiplos aspectos envolvidos, a expansão e construção de instrumentos que permitam ao aluno, progressivamente, ampliar sua competência discursiva (BRASIL, 1998, p.27).

Para que essas atividades tenham esse viés, é preciso que o professor faça um planejamento do que deve ser trabalhado em suas 
aulas. Esse planejamento pode ser realizado a partir de diferentes dispositivos didáticos. $\mathrm{O}$ primeiro dispositivo que pode ser considerado como organizador/ordenador do trabalho docente e que se encontra legitimado nos documentos oficiais é o PL1․

Os PL1 favorecem para "o necessário compromisso do aluno com sua própria aprendizagem, pois contribuem muito mais para o engajamento do aluno nas tarefas como um todo, do que quando essas são definidas pelo professor” (BRASIL, 1998, p.87). De acordo com os PCN, o dispositivo carrega exigências de grande valor pedagógico:

- permitem que o aluno aprenda a produzir textos escritos mais adequados às condições de produção, pelo exercício que o aluno-escritor realiza para ajustar o texto à imagem que faz do leitor, fisicamente ausente;

- colocam de maneira mais acentuada a necessidade de refacção e de cuidado com o trabalho, pois quando há leitores de fato para a escrita dos alunos, a legibilidade passa a ser objetivo deles também, e não só do professor;

- permitem interseção entre os conteúdos de diferentes áreas e/ou entre estes o tratamento dos temas transversais nessas áreas. (BRASIL, 1998, p. 87-88).

Kleiman (2000, apud KLEIMAN, 2007, p.16) define o termo PL ${ }^{1}$ como

um conjunto de atividades que se origina de um interesse real na vida dos alunos e cuja realização envolve o uso da escrita, isto é, a leitura de textos que, de fato, circulam na sociedade e a produção de textos que serão realmente lidos, em um trabalho coletivo de alunos e professor, cada um segundo sua capacidade.

Pautar a leitura e a escrita como prática social significa não diferenciar essas atividades de outras situações fora do ambiente escolar, ou seja, deve envolver uma “atividade coletiva, com vários participantes que têm diferentes saberes e os mobilizam (em geral cooperativamente) segundo interesses, intenções e objetivos individuais e metas comuns” (KLEIMAN, 2007, p.5).

Para Tinoco (2008), os PL ${ }^{1}$ proporcionam um modelo didático alternativo às propostas tradicionais e às SD por agrupamento de gêneros. De acordo com a autora, a construção desse modelo não pode acontecer por meio de substituição ou adaptação de conteúdos, como acontece com outros projetos. Essa especificidade é justificada por esse dispositivo ser caracterizado pela aprendizagem de conteúdos que realmente sejam significativos para a vida e visar ao desenvolvimento de competências linguístico-enunciativo-discursivas, a partir dos usos sociais da escrita em diferentes esferas de atividade. Portanto, segundo a autora, um $\mathrm{PL}^{1}$ pode ser entendido como um modelo didático flexível e adaptável, que dá substância a um processo de ensino-aprendizagem cooperativo requerendo do professor e de seus alunos uma postura de pesquisador: aquele que, na pluralidade que constitui a sua prática profissional, tenha como um de seus objetivos a reflexão, ou seja, “aquele que, ao ensinar, também aprende com o grupo e não tem receio de explicitar o quanto aprendeu na riqueza do processo” (TINOCO, 2009, p. 172).

Um segundo dispositivo considerado como importante para a organização do trabalho do professor é a SD. Dolz, Noverraz e Schneuwly (2013, p.82-83) que a abordam como "um conjunto de atividades escolares organizadas de maneira sistemática, em torno de um gênero textual oral ou escrito”, cuja finalidade é, precisamente, “ajudar o aluno a dominar melhor um gênero de texto, permitindo-lhe, assim, escrever ou falar de uma 
maneira mais adequada numa dada situação de comunicação.”

A SD deve contemplar as características ensináveis do gênero selecionado para a elaboração desse material. Essas características deverão trazer informações como as análises dos contextos (histórico, de produção, circulação) e ao plano textual global do texto, abordando questões referentes à estrutura, aos mecanismos internos e aos mecanismos enunciativos do gênero em questão. Em outras palavras, deve-se construir um Modelo Didático de Gênero (doravante MDG) (DOLZ, SCHNEUWLY, 2013).

Dolz, Gagnon e Decândio (2010, p.48) definem um MDG como “a descrição provisória das principais características de um gênero textual com o objetivo de ensiná-las”, capaz de explicitar dimensões como: os saberes de referência a serem mobilizados para se trabalhar os gêneros; a descrição dos diferentes componentes textuais específicos; as capacidades de linguagem dos alunos, buscando, dessa maneira, orientar as práticas de ensino.

Importante dizer que, embora uma SD dependa da construção de um MDG, este não vem pronto: o professor precisa elaborá-lo. Para isso, é necessário que o profissional reflita não apenas sobre as dimensões ensináveis como a complexidade utilizada para apresentar os elementos pertencentes ao gênero que norteia as atividades daquela SD. Desta forma, é preciso levar em consideração certos aspectos contextuais como, por exemplo, a série e a idade dos alunos em que esse dispositivo didático será desenvolvido. Isso permite que um mesmo gênero possa ser trabalhado em diferentes séries: basta o professor saber como adequar a SD para aquele determinado contexto.

Assim como os $\mathrm{PL}^{1}$ e as $\mathrm{SD}$, as $\mathrm{PL}^{2}$ também são considerados como dispositivos importantes capazes de (inter)mediar o trabalho do professor.

Nascimento e Zirondi (2014, p.265) abordam que uma $\mathrm{PL}^{2}$ acontece dentro de um planejamento didático e compreende em atividades que propiciam "o desenvolvimento de capacidades inerentes às propriedades do gênero de texto (contextuais e de organização interna), sem deixar de lado as dificuldades apresentadas pelos alunos em relação ao sistema da escrita e à gramática”.

Portanto, diferente da SD - em que as atividades são elaboradas de forma sistemática para chegar à finalidade de propiciar o melhor domínio sobre um gênero de texto, como já dissemos - na $\mathrm{PL}^{2}$, as atividades acontecem de forma mais “isolada”, isto é, conforme a necessidade da turma para compreender a aprendizagem de um determinado conteúdo.

Entretanto, como também acontece com os outros dispositivos didáticos, para que uma $\mathrm{PL}^{2}$ seja elaborada, é preciso que o professor faça primeiramente uma reflexão sobre o contexto em que o conteúdo será trabalhado. Nessa reflexão devem-se levar em consideração aspectos como materiais adotados pela instituição, capacidade de linguagem dos alunos, tempo disponível para apresentar o conteúdo, objetivos do professor com aquela determinada turma de alunos, etc. Desta forma, a sua construção pode variar mesmo quando preparado para alunos pertencentes às mesmas séries de ensino.

\section{Metodologia}

Este trabalho tem um caráter qualitativo. Isso significa, nas palavras de de Grande e Kleiman (2007), que esse tipo de pesquisa implica uma preocupação com a maneira como o mundo social é interpretado e experienciado, entendido e produzido, com base em métodos 
de geração de dados flexíveis e sensíveis ao contexto social em que o dado foi motivado.

Com a finalidade de buscar discutir como os dispositivos didáticos podem (inter) mediar e organizar o trabalho docente e, desta forma, auxiliar no ensino-aprendizagem de Língua Portuguesa, escolhemos para compor a análise de dados deste trabalho três materiais: Projeto Taturana; Revistas Recreio e Ciência Hoje para crianças: Despertando para o mundo da leitura e do conhecimento; e Cantigas de Roda: Cantando e brincando também se aprende a ler e escrever.

O primeiro corpus, Projeto Taturanas, nos foi cedido por uma professora atuante em uma instituição municipal de ensino e elaborado pela própria profissional para ser desenvolvido em uma turma de alunos de $3^{\circ}$ ano do Ensino Fundamental I, no ano de 2013. Quanto à estrutura, o material possui 16 atividades, distribuídas em 16 oficinas, guiadas uma a uma por objetivos intencionais, propostas previamente e direcionadas pela professora. Além disso, conta com partes como justificativa, problema, objetivos gerais e específicos (esses voltados para cada disciplina), para o estudo do conteúdo.

Os outros materiais, elaborados por diferentes professoras durante um Curso de Formação Continuada, realizado em 2011, fazem parte da tese de doutorado de Zirondi (2013) e nos foram cedidos pela própria pesquisadora. Em relação à construção, Revistas Recreio e Ciência Hoje para crianças possui 26 atividades distribuídas em 9 oficinas, elaboradas para um público alvo do $3^{\circ}$ ao $5^{\circ}$ ano do Ensino Fundamental I. Já Cantigas de Roda compreende 34 atividades, distribuídas em 6 oficinas e preparadas com a finalidade de atender alunos dos $1^{\circ}$ e $2^{\circ}$ anos do Ensino Fundamental I.

Apresentados os materiais, estabeleceremos algumas categorias para análise a partir dos elementos caracterizadores e a função organizadora de um PL ${ }^{1}$, de uma SD e de uma $\mathrm{PL}^{2}$, de acordo com os autores abordados anteriormente e responsáveis pelos trabalhos envolvendo cada dispositivo didático. No quadro 1 , abordaremos os elementos organizadores de um PL루

Quadro 1: Elementos caracterizadores de um PLํ․

\begin{tabular}{|c|c|}
\hline $\begin{array}{l}\text { ELEMENTOS } \\
\text { CARACTERIZADORES } \\
\text { DE UM PL }\end{array}$ & \\
\hline $\begin{array}{l}\text { Aulas centradas nos } \\
\text { alunos }\end{array}$ & O aluno precisa ser o centro de atenção do professor; \\
\hline $\begin{array}{l}\text { Desenvolvimento de } \\
\text { tarefas }\end{array}$ & $\begin{array}{l}\text { Atividades não podem ser apenas direcionadas, mas, sobretudo, devem } \\
\text { exercitar a autonomia do aluno para a construção de seu conhecimento; }\end{array}$ \\
\hline Resolução de problemas & $\begin{array}{l}\text { Busca de alternativas de solução para um problema de ação (ou não) } \\
\text { social. Para isso, as ações desenvolvidas precisam contar com a parceria } \\
\text { entre professores e alunos; }\end{array}$ \\
\hline $\begin{array}{l}\text { Interação entre os } \\
\text { agentes }\end{array}$ & $\begin{array}{l}\text { Os professores devem descentralizar o ensino de sua figura e concentrar } \\
\text { na interação entre ele e seus alunos para que ocorra o ensino, pois o } \\
\text { conhecimento deve ser visto como iniciativas sociais e não transferido } \\
\text { de indivíduo por indivíduo; }\end{array}$ \\
\hline $\begin{array}{l}\text { Aluno como sujeito do } \\
\text { conhecimento }\end{array}$ & $\begin{array}{l}\text { O professor deve conscientizar seus alunos sobre os benefícios que } \\
\text { aquela determinada aprendizagem trará não só para sua vida, mas para } \\
\text { o grupo todo; }\end{array}$ \\
\hline
\end{tabular}


conclusão

\begin{tabular}{|l|l|}
\hline $\begin{array}{l}\text { ELEMENTOS } \\
\text { CARACTERIZADORES } \\
\text { DE UM PL1 }\end{array}$ & Leitura e escrita como \\
prática social & $\begin{array}{l}\text { Quando propostas para os alunos, as atividades de leitura e escrita } \\
\text { devem possuir uma função diferente de apenas aprender a ler/escrever. } \\
\text { Dessa maneira, tornam-se atividades significativas para o ensino; }\end{array}$ \\
\hline $\begin{array}{l}\text { Atividades } \\
\text { contextualizadas }\end{array}$ & $\begin{array}{l}\text { As atividades precisam estar inter-relacionadas de uma maneira que } \\
\text { propiciem aos alunos motivos e objetivos para atingir alguma finalidade } \\
\text { (solicitar mudanças, promover melhorias, etc.); }\end{array}$ \\
\hline $\begin{array}{l}\text { Desterritorialização dos } \\
\text { lugares de aprendizagem }\end{array}$ & $\begin{array}{l}\text { É importante que a aprendizagem não ocorra apenas na sala de aula, } \\
\text { mas também em outros espaços dentro e fora da escola; }\end{array}$ \\
\hline Tempo escolar & $\begin{array}{l}\text { O professor deve controlar o tempo de duas maneiras: por um } \\
\text { cronograma e por uma sequência lógica de atividades e tarefas com as } \\
\text { etapas necessárias para cumpri-las; }\end{array}$ \\
\hline Distribuição de tarefas & $\begin{array}{l}\text { A distribuição de tarefas feita pelo professor deve ser coerente com os } \\
\text { conhecimentos prévios dos alunos e com a capacidade de pesquisar } \\
\text { novas informações para integrá-las à situação em um processo } \\
\text { permanente de compartilhamento; }\end{array}$ \\
\hline $\begin{array}{l}\text { Inserção em uma rede de } \\
\text { comunicação }\end{array}$ & $\begin{array}{l}\text { Consonância entre o universo escolar com a vida social e as } \\
\text { necessidades cotidianas dos cidadãos, ou seja, a uma aproximação de } \\
\text { diferentes sujeitos e instituições (família, escola, trabalho, etc.); }\end{array}$ \\
\hline $\begin{array}{l}\text { Instrumentos materiais e e } \\
\text { simbólicos }\end{array}$ & $\begin{array}{l}\text { O professor deve fazer uso de recursos mediacionais para que haja a } \\
\text { construção do aprendizado dos alunos. Dessa maneira, pode ser feito o } \\
\text { uso de computadores, revistas, jornais, livros e TV, etc. }\end{array}$ \\
\hline
\end{tabular}

Através desse conjunto de elementos, os PL $^{1}$ são capazes de promover um ensino que venha a considerar os interesses dos alunos em relação à sociedade ou a aspectos de sua própria aprendizagem. Com isso, esse dispositivo didático pode trazer uma aproximação de diferentes áreas de conhecimento, além de “transformar objetos circulares como 'escrever para aprender a escrever’ e 'ler para aprender a ler' em ler para compreender e aprender aquilo que foi relevante para o desenvolvimento e a realização do projeto”. (KLEIMAN, 2000 apud TINOCO, 2008, p. 162).

No quadro 2, temos as etapas para a construção de uma SD:

Quadro 2: Estrutura básica para a elaboração de uma SD

\begin{tabular}{|l|l|}
\hline $\begin{array}{l}\text { ESTRUTURA } \\
\text { BÁSICA PARAA } \\
\text { ELABORAÇÃO DE } \\
\text { UMA SD }\end{array}$ & \\
\hline $\begin{array}{l}\text { Apresentação da } \\
\text { situação }\end{array}$ & $\begin{array}{l}\text { Descrição detalhada de um problema de comunicação bem definido para } \\
\text { a classe. Constitui em uma etapa de extrema importância, visto que é a } \\
\text { partir dela que se constrói a percepção dos alunos a respeito do trabalho } \\
\text { que será realizado e os prepara para a produção final; }\end{array}$ \\
\hline
\end{tabular}


conclusão

\begin{tabular}{|l|l|}
\hline $\begin{array}{l}\text { ESTRUTURA } \\
\text { BÁSICA PARA A } \\
\text { ELABORAÇÃO DE } \\
\text { UMA SD }\end{array}$ & \\
\hline Produção inicial & $\begin{array}{l}\text { Elaboração de um texto oral ou escrito correspondente ao gênero } \\
\text { a ser trabalhado. Isso permite ao professor (re)conhecer o nível de } \\
\text { conhecimentos prévios do aluno a respeito do gênero e, desta forma, } \\
\text { construir atividades que possam suprir as necessidades da turma; }\end{array}$ \\
\hline Módulos & $\begin{array}{l}\text { Constituídos por várias atividades ou exercícios, são organizados a partir } \\
\text { dos problemas detectados na primeira produção. Tem a finalidade de dar } \\
\text { aos alunos os instrumentos necessários para superá-los e, desta forma, } \\
\text { chegar a uma boa produção final; }\end{array}$ \\
\hline Produção final & $\begin{array}{l}\text { Possibilita ao aluno pôr em prática os conhecimentos adquiridos ao } \\
\text { longo do processo do trabalho com a SD e, ao professor, a oportunidade } \\
\text { de realizar uma avaliação somativa. }\end{array}$ \\
\hline
\end{tabular}

É importante ressaltar que, ao escolher realizar o trabalho escolar a partir desse dispositivo, o professor deve contemplar um gênero que o aluno não domina ou o faz de maneira insuficiente, ou então sobre aqueles dificilmente acessíveis, espontaneamente, pela maioria dos alunos e sobre os gêneros públicos e não-privados. As SD servem, portanto, para dar acesso aos alunos a práticas de linguagem novas e dificilmente domináveis (DOLZ; NOVERRAZ, SCHNEUWLY, 2013).

Os aspectos caracterizadores de uma $\mathrm{PL}^{2}$ são abordados no quadro 3:

Quadro 3: Aspectos caracterizadores de uma PL $^{2}$

\begin{tabular}{|l|l|}
\hline $\begin{array}{l}\text { ASPECTOS } \\
\text { CARACTERIZADORES } \\
\text { DE UMA PL }\end{array}$ & \\
\hline Tema gerador & $\begin{array}{l}\text { Definição do tema ou gênero que será apresentado aos alunos e, desta } \\
\text { forma, norteará as atividades. Essa escolha depende de alguns fatores } \\
\text { como material adotado, a complexidade, o objetivo do professor com os } \\
\text { conteúdos que serão trabalhados naquele contexto, etc.; }\end{array}$ \\
\hline Projeto didático & $\begin{array}{l}\text { O professor deverá pensar não apenas em como desenvolver e organizar } \\
\text { os conteúdos e atividades que deverão ser trabalhadas em torno do tema } \\
\text { escolhido, como planejar o tempo que será gasto para a realização dessa } \\
\text { prática; }\end{array}$ \\
\hline $\begin{array}{l}\text { Modelo Didático de } \\
\text { Gênero }\end{array}$ & $\begin{array}{l}\text { Momento necessário para o professor decidir quais as dimensões } \\
\text { (aspectos dos gêneros) ensináveis para os alunos; }\end{array}$ \\
\hline SD & $\begin{array}{l}\text { Elaboração das atividades que melhor atendam às necessidades da } \\
\text { turma em relação ao conteúdo ensinado; }\end{array}$ \\
\hline Avaliação do processo & $\begin{array}{l}\text { Avaliação do professor quanto o trabalho realizado com a PL }{ }^{2} \text {. Deve } \\
\text { levar em consideração se o planejamento realizado no projeto didático } \\
\text { trouxe o resultado que era esperado para aquela turma. }\end{array}$ \\
\hline
\end{tabular}


Através da utilização do dispositivo, nas $\mathrm{PL}^{2}$ que perpassam o domínio da escrita, os alunos tomam consciência dos desafios que se apresentam escrevendo e dão ao texto escrito à função que lhe corresponde nas práticas sociais: ele deve ser objeto para a interação entre locutor e leitor (NASCIMENTO, ZIRONDI, 2014).

\section{Análise de dados}

A partir da apresentação dos materiais que escolhemos para compor nossas análises e da definição das categorias com base nos elementos caracterizadores de cada dispositivo didático, podemos abordar alguns dos aspectos observáveis concernentes aos dispositivos didáticos para, desta forma, chegar às reflexões que propusemos no início deste artigo.

\section{$P L^{1}$}

Projeto Taturanas será alvo de reflexões acerca dos elementos do primeiro dispositivo didático apresentado neste trabalho: os PLํ.

De acordo com a justificativa apresentada pela professora responsável pela elaboração do material, o trabalho desenvolvido teve como parâmetro a curiosidade dos alunos ao observar uma taturana levada para a sala de aula por um deles. Com isso, a finalidade de trabalhar esse conteúdo era a de favorecer um maior conhecimento sobre esse inseto.

Para cumprir com esse objetivo, a profissional organizou 16 oficinas, as quais envolveriam atividades: a respeito do diagnóstico (oficinas 1 e 3);observação da taturana, suas características e a classificação como animal invertebrado (oficina 2); elaboração de questionário (oficina 4); construção de gráfico (oficina 5); pesquisas sobre espécie das taturanas (oficina 6), onde vivem (oficina
7), fases do ciclo vital (oficina 8) e formas de prevenção para que não ocorra "queimaduras" com o inseto (oficina 9); inserção da língua inglesa a partir do trabalho com o livro A lagarta muito faminta (oficina 10); identificação sobre as principais diferenças entre mariposas e borboletas (oficina 11); pesquisa sobre como as taturanas "queimam" (oficina 12) e a comparação de sua queimadura com a queimadura da água-viva (oficina 13); visitas para aprofundamento do conhecimento (uma bióloga, oficina 14; uma pessoa "queimada" pelo inseto, oficina 15); e, por fim, uma autoavaliação dos alunos sobre os conteúdos que foram abordados no decorrer do material (oficina 16), além de uma apresentação do que foi aprendido nas oficinas para as famílias (denominado pela professora como culminância). Desse modo, o material envolve conteúdos de diferentes disciplinas, tendo caráter interdisciplinar.

A primeira categoria definida para analisar um material como um $\mathrm{PL}^{1}$ é aulas centradas nos alunos. Projeto Taturanas traz esse elemento em dois momentos: na parte destinada à justificativa para sua realização e, na primeira oficina, denominada como construir índices dos alunos. Essa atividade, guiada pelo objetivo de sondar o que os alunos já sabem sobre as taturanas e fazer um levantamento do que querem aprender, demonstra certo cuidado da profissional ao tratar essa aprendizagem de uma maneira realmente significativa para as crianças, uma vez que o conteúdo a ser trabalhado foi escolhido por elas.

O desenvolvimento de tarefas é outro elemento presente em um PL ${ }^{1}$. Através dele, é importante que as atividades não sejam apenas direcionadas, mas, sobretudo, que exercitem a autonomia do aluno para a construção do conhecimento. No caso do material analisado, as atividades parecem ser elaboradas das duas formas. Um exemplo da primeira (apenas direcionadas) é a oficina 4: 
Os alunos irão criar um questionário para realizar uma pesquisa com a sua família, explorando o gênero, a sua estrutura e a sua função social.

1) Existem taturanas em sua casa?

2) Com que frequência elas aparecem?

3) Alguém da sua família já foi queimado por taturana? Quais foram as providências tomadas?

Fonte: oficina 4 - Questionário "investigatível”

Se a proposta fosse apenas o enunciado da criação de um questionário pelos alunos, essa atividade seria uma forma de buscar desenvolver essa autonomia, de acordo com as curiosidades, necessidades, conhecimentos e interesses dos alunos. Entretanto, logo abaixo da descrição, aparecem questões que podem ter sido elaboradas previamente pela professora. Caso isso tenha acontecido, a proposta passa de autônoma para direcionada por ocasionar que os alunos voltem para a sala de aula, após o cumprimento da atividade, com respostas previsíveis e muito parecidas com as dos colegas da turma.

Já um exemplo de atividade como forma de promover autonomia está descrita na oficina 9:

Colher informações com a família sobre os possíveis cuidados que temos que ter com as taturanas e quais as atitudes devemos tomar em caso de contato com esse animal. Depois da coleta de informações e da pesquisa científica elaborar uma lista de cuidados e atitudes que devem ser tomadas em relação às taturanas.

Fonte: oficina 9 - Prevenção

Essa oficina apresenta como objetivo conhecer as principais prevenções em caso de acidentes com taturanas. Além de parecer promover a autonomia dos alunos em fazer uma lista de cuidados e atitudes com base nas informações que recebessem da família com relação ao inseto, a proposta pode se enquadrar também em outro aspecto que deve estar presente na elaboração de um PL ${ }^{1}$ : a leitura e a escrita como prática social. Para Kleiman (2000), a escrita, nesse viés, é utilizada para atender algum outro fim. No caso do material, a de promover informações sobre as principais prevenções.

Apesar de não se tratar de um problema social, Projeto Taturanas apresenta uma questão considerada como o problema para a aprendizagem: "As taturanas viram borboletas?”. Essa questão também cumpre outro aspecto a ser considerado na elaboração desse instrumento de ensino: a resolução de problemas. Entretanto, apesar de ser apresentado um conflito - que provavelmente surgiu de uma curiosidade levantada pela turma em que o material foi trabalhado - o material não deixa claro se foi isso resolvido ao final do projeto, pois evidencia o processo e não os resultados.

Outros elementos que devem ser levados em consideração pelo professor para a elaboração de um PL ${ }^{1}$ são a desterritorialização dos lugares de aprendizagem, a inserção em uma rede de comunicação e o tempo escolar.

No caso do material analisado, tanto a desterritorialização quanto a inserção em uma rede de comunicação parecem ocorrer nas oficinas 14 (visita da bióloga) e 15 (visita de uma pessoa “queimada” por taturana), pois podem cumprir os mesmos objetivos que, provavelmente, seriam traçados com uma aula itinerante (no caso, com a visita da bióloga, ajudar os alunos a compreender e tirar dúvidas com relação às taturanas; através do relato feito pela pessoa “queimada”, apresentar o que 
foi relatado em forma de um texto narrativo), como promover uma oportunidade de interação entre sujeitos (alunos, bióloga, vítima de taturanas, etc.) de diferentes instituições (escola, laboratório de biologia, etc.).

Em relação ao tempo escolar, o material analisado traz esse elemento em forma, primeiramente, de objetivos específicos para ser atingidos em cada disciplina (por exemplo, em Língua Portuguesa, a familiarização com diferentes gêneros textuais que envolvam tipologias discursivas como narração, descrição, explicação, exposição, etc; em Ciências, identificar as principais causas do surgimento das taturanas, conhecer as diferentes espécies e as precauções necessárias que devem ser tomadas para o contato com o inseto, etc.) e, depois, nas próprias atividades elaboradas nas oficinas, que parecem cumprir com tais objetivos.

Portanto, Projeto Taturanas, assim como denominado pela professora, carrega marcas do dispositivo didático $\mathrm{PL}^{1}$ como: 0 assunto ter sido originado de um interesse real da vida dos alunos, o uso da leitura e da escrita como prática social, além de envolver oficinas que muito se aproximavam de outros elementos necessários para a elaboração de um PL1ㅗㄹ como abordamos no decorrer da análise.

$S D$

Revistas Recreio e Ciência Hoje para crianças: despertando para o mundo da leitura e do conhecimento será responsável pelas nossas reflexões acerca do dispositivo SD.

Como se pode notar pelo título, o material compreende o estudo de duas revistas infantis, e todas as atividades são elaboradas para serem realizadas em grupos e foram compostas por 9 oficinas, organizadas da seguinte forma: oficina 1 - denominada como conhecendo as revistas, tem o intuito não apenas de apresentar como também de comparar as duas revistas infantis ; oficina 2 - os contextos: histórico, de produção e circulação das Revistas, trabalha com atividades sobre os referidos contextos, tanto da Revista Recreio quanto da Ciência Hoje para crianças; oficina 3 a 8 - cada uma aborda um gênero pertencente às revistas infantis: conhecendo o gênero capa; sumário; explorando as propagandas; jogos (entretenimento); texto instrucional; e textos informativos, respectivamente; já a oficina 9, denominada como elaborando uma revista, compreende a junção dos gêneros trabalhados em oficinas anteriores, propiciando, assim, a confecção de revistas feitas pelos próprios alunos.

Como já abordamos no quadro 2 deste trabalho, os aspectos para a elaboração de uma SD, de acordo com Dolz, Noverraz e Schneuwly (2013) são: apresentação da situação, primeira produção, módulos e produção final.

A primeira atividade do material analisado é descrita da seguinte maneira:

Atividade 1: Apresentação das Revistas. Levaremos para a sala de aula um número considerável de revistas Recreio e Ciência Hoje para Crianças que ficarão à disposição dos alunos estrategicamente em um espaço visível da sala. A proposta é que eles leiam e explorem a diversidade dos textos existentes nessas revistas. Iniciar uma conversa sobre o que já conhecem, qual delas eles preferem, quais os assuntos específicos de cada uma.

Fonte: oficina 1 - conhecendo as revistas

A estratégia utilizada para essa atividade (distribuição de vários exemplares das revistas em espaços visíveis da sala de aula) é uma maneira de apresentar o material que deverá ser trabalhado naquela turma. Isso, junto 
com a conversa iniciada pela professora após ser aguçada a curiosidade dos alunos, configuram no que Dolz, Noverraz e Schneuwly (2013) abordam como apresentação da situação.

A próxima atividade, ainda apresentada na oficina 1 , conhecendo as revistas é a seguinte:

“Atividade 2: Construção de cartazes.
Dividir a turma em 2 grupos e sortear uma
revista para cada grupo. No cartaz, os gru-
pos deverão montar um infográfico (dese-
nho que representa o objeto), “desmontan-
do” a revista. Deverão explicar cada parte
dela: o que a compõe, o funcionamento, as
sessões - capa, sumário, editorial, artigos,
reportagens, propagandas, passatempos,
tiras, piadas, diversidade etc...

Fonte: oficina 1: conhecendo as revistas

A primeira produção, segunda etapa para a construção de uma SD, propõe que os alunos produzam um texto, uma vez que este é o momento de o professor (re)conhecer o nível de conhecimentos prévios do aluno a respeito do gênero a ser trabalhado (DOLZ; NOVERRAZ, SCHENEUWLY, 2013). A atividade 2, descrita acima, não solicita a escrita de um texto, mas, a partir da construção dos cartazes e com a proposta de “desconstruir" a revista, focaliza uma primeira produção. Isso porque, com essa “desconstrução”, os alunos precisariam explicar cada sessão e, a partir dessa explicação, a professora conseguiria (re)conhecer o nível de conhecimentos prévios dos grupos e, desta forma, pensar em uma melhor forma de organizar a próxima etapa da SD: os módulos.

As atividades destinadas aos módulos são organizadas a partir da oficina 3 até a 8, cada uma focalizando um gênero presente nas revistas, como já dissemos. Nessas oficinas, compostas por no máximo quatro atividades cada, se propõe, inicialmente, uma investigação a respeito do gênero que será trabalhado naquele momento, o que acontece de maneiras variadas: por exemplo, para trabalhar o gênero capa, a professora apresenta várias capas em slides; no sumário, solicita que os alunos busquem a definição da palavra no dicionário, para assim, descobrirem a sua finalidade; no trabalho com as propagandas, deveriam destacá-las nas revistas e responder algumas questões como a quem são dirigidas, quais elementos demonstram isso, etc.; para os jogos (entretenimento), a professora propõe uma discussão sobre o que pode ser considerado entretenimento, depois da palavra ser procurada no dicionário; em texto instrucional, é solicitado como tarefa que os alunos tragam para a sala de aula textos que demonstrem esse gênero (bulas de remédio, manuais de instruções, receitas, regras de jogos) e, em grupos, respondam algumas questões a respeito desses materiais; por fim, para trabalhar textos informativos, a professora propõe que cada aluno leia uma revista, selecione os textos que tenham essa finalidade, selecione um para ser apresentado para o restante da turma, para que sejam respondidas algumas questões.

Já a última atividade de cada oficina tem a função de consolidar o que foi aprendido, uma vez que é solicitado que se faça uma produção (de maneiras variadas) demonstrando aquele gênero, como: elaboração de uma ficha técnica, a partir de um roteiro, para o gênero capa; elaboração de um sumário a partir dos conteúdos presentes em uma revista; produção de uma propaganda; elaboração de uma lista de entretenimento e a criação de atividades e jogos que os alunos consideram ser desta forma; montar jogos a partir de sucatas e escrever um texto instrucional sobre ele; e o preenchimento de uma ficha técnica a partir de textos informativos sobre animais. 
Em relação à produção final, acreditamos que ela se encontra durante toda a Oficina 9 , composta por quatro atividades e destinadas à elaboração de uma revista. No primeiro exercício da oficina, pede-se que os alunos, organizados em grupos, selecionem trabalhos já produzidos por eles em outros momentos (textos informativos instrucionais, notícias, propagandas, etc.), para que, com a ajuda da professora, passem por uma revisão (de coesão, coerência, ortográfica e gramatical) e, após isso, possam ser publicados; na segunda atividade, com os textos já selecionados, organizados e revisados, os alunos deveriam elaborar o sumário e numerar as páginas; no terceiro exercício, cada grupo deveria escolher o texto mais interessante para compor a capa, levando em consideração os aspectos visuais e verbais (manchete); por fim, a última atividade seria, após encadernar as revistas, expô-las na biblioteca para divulgação do trabalho da classe.

Através desse conjunto de atividades propostas na oficina, como disseminado por Dolz, Noverraz e Schneuwly (2013), foi possibilitado que os alunos colocassem em prática o que foi aprendido sobre o gênero em questão, no decorrer de todas as oficinas.

\section{$P L^{2}$}

O terceiro material a ser analisado neste trabalho é Cantigas de Roda: Cantando e brincando também se aprende a ler e escrever. Ao abordar as cantigas de roda, as oficinas compreendem em atividades sobre diagnóstico sobre o gênero (oficina 1), análise de cantigas de roda (oficina 2), compreensão de sua linguagem (oficina 3), trabalho com aspectos de intertextualidade (oficina 4), cultivo do cravo (oficina 5) e coletânea de cantigas de roda (oficina 6).
Assim como no caso anterior, a professora acredita que suas atividades foram elaboradas dentro do dispositivo SD. Por isso, traremos algumas atividades e utilizaremos as categorias definidas para ele:

Atividade 1: apresentação das Cantigas de Rodas. Entrei na sala cantando uma Cantiga de Roda, “Terezinha de Jesus”. Perguntei a eles se sabiam o porquê estava cantando antes de iniciar a aula, se conheciam aquela música. Após diferentes respostas, disse que estava com saudade da melhor época da minha vida, a infância. Disse-lhes ainda que, quando tinha a idade deles, eu brincava de Cantigas de Roda no recreio junto com as meninas e os meninos de minha escola.

Fonte: oficina 1 - Diagnóstico sobre o gênero Cantigas de Roda

Como já abordado, a primeira etapa para a construção de uma SD é a apresentação da situação. Nela é preciso, de acordo com Dolz, Noverraz e Schneuwly (2013), que o professor apresente aos alunos, de maneira detalhada, uma determinada situação de comunicação para ser realizada. No caso do material analisado, a atividade 1 descrita acima, parece cumprir com esse elemento, uma vez que, através das atitudes tomadas pela professora (entrar na sala de aula cantando uma cantiga, sondar, através de questionamentos, se os alunos conheciam aquela canção e sabiam o porquê de tê-la cantado, e a partir das respostas, ter contado sobre suas brincadeiras de infância), o gênero foi apresentado para a turma.

Ainda na oficina 1, após os alunos terem ido à quadra da escola para brincarem e aprenderem algumas cantigas, há a seguinte proposta de atividade: 
Atividade 3: distribuí uma folha de papel sulfite em branco para que desenhassem e escrevessem a cantiga de que mais gostaram (intervenção individual).

Fonte: oficina 1 - Diagnóstico sobre o gênero de texto Cantigas de Roda.

Com base nas categorias definidas para a SD, essa atividade compreenderia a segunda etapa da construção desse dispositivo: $a$ produção inicial.

Em relação aos módulos, etapa seguinte para a elaboração de uma SD, o material analisado traz textos sobre o gênero (cantigas como Terezinha de Jesus, O Cravo e a Rosa), mas seguidos de propostas de atividades geralmente voltadas para uma abordagem de outros conteúdos como: noções de encontro consonantal (oficina 3, atividade 8), identificação dos mesmos versos em diferentes caligrafias (oficina 4, atividade 4); noções de substantivos comuns e próprios (oficina 4, atividade 5); cultivo do cravo (oficina 5, atividade 1), etc. Desse modo, os textos do gênero são utilizados não para melhor dominá-lo, mas apenas como pretexto para a aprendizagem de conteúdos específicos.

Aúltima proposta de atividade presente no material é a seguinte:

Atividade 2: sugeri, então, que elaborássemos um painel com as Cantigas mais populares e com textos informativos sobre o que seria, onde são encontradas, quem canta e compõe entre outros aspectos. Os alunos pesquisaram e usamos essas informações na montagem do painel que foi exposto no pátio para o conhecimento de todos.

Fonte: oficina 6 - Coletânea de Cantigas de Roda
De acordo com a estrutura apresentada por Dolz, Noverraz e Schneuwly (2013), o elemento seguido aos módulos é a produção final. No material analisado, há essa produção (montagem de um painel que deveria ser exposto no pátio do colégio com informações a respeito do gênero), entretanto, essas informações só foram solicitadas pela professora nesse momento. $\mathrm{O}$ fato de as outras oficinas terem sido voltadas à aprendizagem de conteúdos que não apresentassem uma apropriação do gênero, mas o ensino de conteúdos específicos da Língua Portuguesa, essa produção não focaliza o progresso do estudo do gênero.

Diante isso, o material analisado se distancia do dispositivo que a profissional acredita ter elaborado - SD - e aproxima-se mais de uma $\mathrm{PL}^{2}$. A razão para ser considerado dessa forma vem, sobretudo, devido às atividades elaboradas para o material serem vistas como quase que esporádicas, isoladas, cada uma contemplando um objetivo específico. Assim, além do foco da aprendizagem ser o estudo do gênero Cantigas de Roda, este serve apenas como um tema para exercícios que são elaborados objetivando o ensino de outros aspectos da disciplina de Língua Portuguesa.

\section{Considerações finais}

Propomos aqui, buscar a compreensão quanto ao funcionamento de três dispositivos didáticos capazes de mediar a elaboração e a organização do trabalho do professor: os $\mathrm{PL}^{1}$, as $\mathrm{SD}$ e as $\mathrm{PL}^{2}$.

Embora possam auxiliar o processo de ensino e aprendizagem da disciplina de Língua Portuguesa, cada dispositivo possui aspectos e objetivos distintos. Pudemos compreender melhor esses aspectos ao analisarmos os materiais Projeto Taturanas, Revistas Infantis e Cantigas de Roda, elaborados por 
professoras de diferentes instituições municipais de ensino.

Quanto aos objetivos de cada dispositivo, se os colocarmos em uma escala, os $\mathrm{PL}^{1}$ podem ser considerados os de maior abrangência, pois não apenas trazem uma aprendizagem que seja de interesse real dos alunos, como perpassam o ensino na sala de aula. Contudo, para que aconteça um $\mathrm{PL}^{1}$, é preciso que este abarque também outros dispositivos como as $\mathrm{SD}$ e as $\mathrm{PL}^{2}$ : $\mathrm{SD}$, pois as atividades elaboradas em um $\mathrm{PL}^{1}$, geralmente, são "guiadas” por um gênero de texto e, como vimos, este é o dispositivo “responsável” para tal apropriação, uma vez em que, ao elaborá-lo em conjunto com um Modelo Didático de Gênero, pode-se trabalhar desde seus contextos (histórico, de produção e circulação) até todo o seu plano global (envolvendo estrutura, mecanismos internos e enunciativos); $\mathrm{PL}^{2}$, com a finalidade de trabalhar aspectos pontuais que possam parecer no decorrer da aprendizagem do conteúdo. Deste modo, ao pensarmos em nossa escala, o dispositivo $\mathrm{PL}^{2}$ seria o menos abrangente.

Em relação a como o trabalho do professor pode ser organizado a partir desses diferentes dispositivos, podemos dizer que isso dependerá do que se espera alcançar em uma determinada situação. Portanto, o PL ${ }^{1}$ deve ser utilizado quando o professor objetiva uma aprendizagem que "ultrapasse as paredes da sala de aula”, ou seja, quando há tempo para realizar aulas itinerantes ou até mesmo visitas de outros profissionais na instituição, tudo com o intuito de enriquecer a aprendizagem daquele conteúdo. A SD pode ser a escolha daquele profissional que não pretende "sair" do espaço da sala de aula, mas que tem como objetivo da aprendizagem promover um melhor conhecimento de um determinado gênero (ou hipergênero) para os seus alunos. Por sua vez, o professor que objetivar uma aprendizagem de um conteúdo específico e que não envolva todo o contexto de um gênero, por exemplo, pode ter como escolha uma $\mathrm{PL}^{2}$.

Sabemos que tanto organizar, quanto projetar e planejar aulas constitui-se como tarefa primordial do professor. Desta forma, acreditamos que este trabalho se torna relevante à medida que busca esclarecer aspectos específicos em relação aos diferentes dispositivos didáticos, pois, ao serem esclarecidas as particularidades de cada um, o professor poderá escolher aquele que melhor se adapte às suas necessidades.

\section{Referências bibliográficas}

BRASIL. Secretaria de Educação Fundamental. Parâmetros Curriculares nacionais: terceiro e quarto ciclos do ensino fundamental: língua portuguesa / Secretaria de Educação Fundamental. Brasília: MEC / SEF, 1998.

DE GRANDE, P. B.; KLEIMAN, A. B. Desafios da pesquisa qualitativa: um percurso metodológico inicial. Língua, Literatura e Ensino, Campinas, maio/2007, vol. II. Disponível em: http:/www.iel.unicamp.br/ revista/index.php/lle/article/viewFile/10/7. Acesso em: 27 jun. 2013.

DOLZ, J.; GAGNON, R.; DECÂNDIO, F. R. Os Gêneros Textuais como unidades de trabalho. In: DOLZ, J.; GAGNON, R.; DECÂNDIO, F. R. Produção escrita e dificuldades de aprendizagem. Adaptação Joaquim Dolz e Fabrício Decândio; tradução Fabrício Decândio e Anna Rachel Machado. Campinas: Mercado das Letras, 2010.

DOLZ, J.; NOVERRAZ, M.; SCHNEUWLY, B. SD para o oral e a escrita: apresentação de um procedimento. In: SCHNEUWLY, B.; DOLZ, J. et all. Gêneros orais e escritos na escola. 3. ed. Campinas: Mercado das Letras. 2013. 
KLEIMAN, A. Letramento e suas implicações para o ensino de língua materna. Signo. Santa Cruz do Sul, v. 32 n 53, p. 1-25, dez, 2007.

NASCIMENTO, E. L.; ZIRONDI, M. I. Gêneros textuais em práticas de alfabetização e letramento. In: NASCIMENTO, E. (Org.). Gêneros textuais: da didática das línguas aos objetos de ensino. $2^{\circ} \mathrm{ed}$. Campinas: Pontes Editores, 2014.

NASCIMENTO, E. L. A dupla semiotização dos objetos de ensino-aprendizagem: dos gestos didáticos fundadores aos gestos didáticos específicos. Signum. Estudos da Linguagem. Revista do Programa de Pós-graduação em estudos da Linguagem. Universidade Estadual de Londrina. n.1/ julho de 2011.

SCHNEUWLY, B.; DOLZ, J. Gêneros orais e escritos na escola. Tradução e Organização de Roxane Rojo e Glaís Sales Cordeiro. $3^{\circ}$ ed. Campinas: Mercado das Letras, 2013.

SCHNEUWLY, B. Gêneros e tipos de discurso: considerações psicológicas e ontogenéticas. In: SCHNEUWLY, B.; DOLZ, J. Gêneros orais e escritos na escola. Tradução e Organização de Roxane Rojo e Glaís Sales Cordeiro. $3^{\circ}$ ed. Campinas: Mercado das Letras, 2013.

TINOCO, G. M. A. de M. Projetos de letramento: ação e formação de professores de língua materna. 2008. 254 f. Tese (Doutorado) - Universidade Estadual de Campinas, Instituto de Estudos de Linguagem. Campinas: [s.n.], 2008.

TINOCO, G. A. Usos sociais da escrita + Projetos de Letramento = Ressignificação do ensino de Língua Portuguesa. In: GONÇALVES, Adair Vieira; BAZARIM, Milene (Org.). Interação, gêneros e letramento: a (re) escrita em foco. São Carlos: Claraluz, 2009.

VIGOTSKY, L. S. Pensamento e linguagem. 1 ed. São Paulo: Martins Fontes, 1987.

ZIRONDI, M. I. Professor formador e professor em formação: uma teia colaborativa para aprendizagens e desenvolvimento. 2013. 366p. Tese (Doutorado em Estudos da Linguagem) - Universidade Estadual de Londrina, Londrina, 2013. 